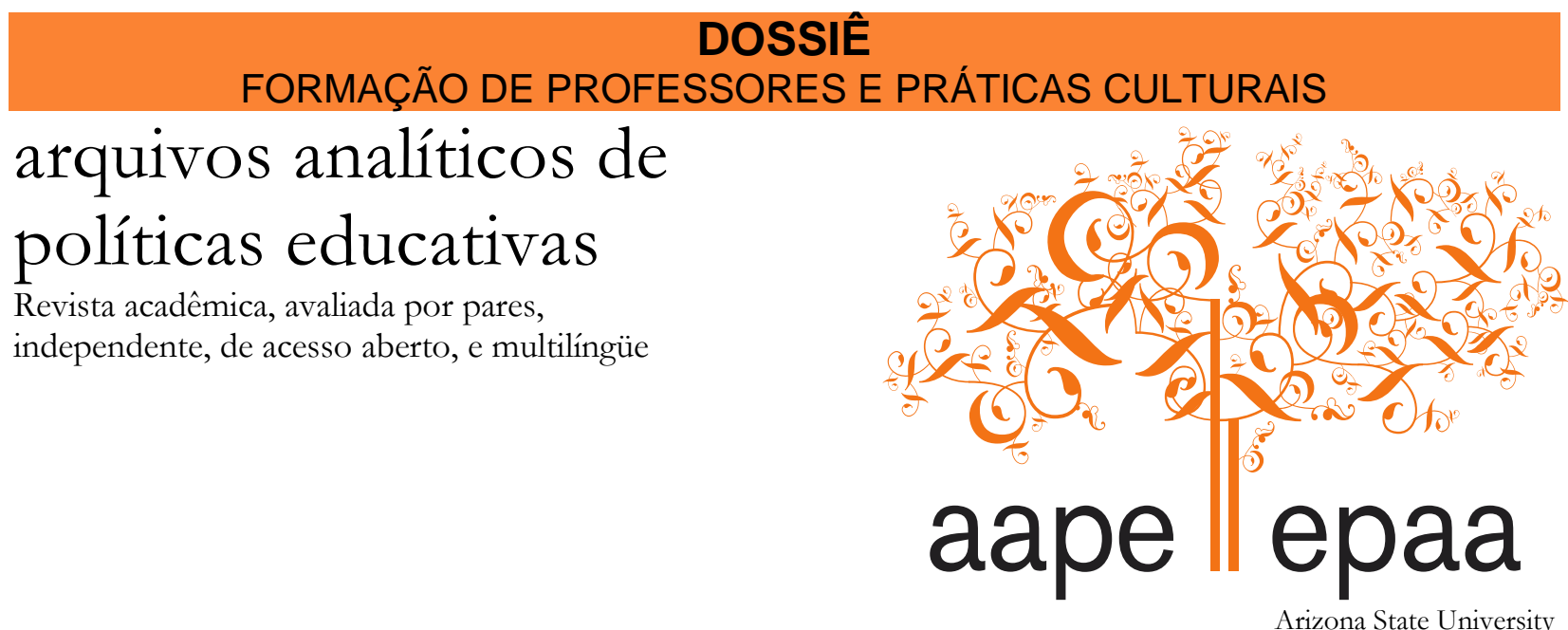

Arizona State University

\title{
Formação de Professores e Práticas Culturais: descobertas, enlaces, experimentações
}

\author{
Carla Beatriz Meinerz. \\ Dóris Maria Luzzardi Fiss \\ Sônia Mara Moreira Ogiba \\ Universidade Federal do Rio Grande do Sul - UFRGS \\ Brasil
}

Citação: Meinerz, C.B.; Fiss, D.M.L.; Ogiba, S.M.M. (2013) Formação de Professores e Práticas Culturais: descobertas, enlaces, experimentações. Arquivos Analíticos de Políticas Educativas, 21 (22). Dossiê Formação de professores e práticas culturais: descobertas, enlaces, experimentações. Editoras convidadas: Carla Beatriz Meinerz, Dóris Maria Luzzardi Fiss \& Sônia Mara Moreira Ogiba. Recuperado [data] http://epaa.asu.edu/ojs/article/view/1140

Formação docente e práticas culturais: descobertas, enlaces, experimentações Resumo: O Dossiê Formação de professores e práticas culturais é constituído por nove textos que consideram as interfaces estabelecidas entre a formação docente, as licenciaturas e os cursos realizados por docentes que atuam na Educação Básica. Ele pretende ser um espaço de socialização de trabalhos propostos por professores universitários que assumem perspectivas teóricas diferentes, mas se aproximam pelo compromisso firmado com as histórias do cotidiano da escola, dos licenciandos em suas inquietações e estarrecimentos, da docência como invenção que se (re)faz a partir do exercício rigoroso de pesquisa e reflexão sobre a própria prática. Este Dossiê expressa uma pluralidade de vozes e concepções, práticas e enlaces presentes no cotidiano da Formação Docente desde a perspectiva da universidade no seu diálogo com espaços escolares plurais em suas culturas, olhares e vozes. Uma pluralidade de experimentações sobre as quais 
nos falam os autores e que transitam por memoriais produzidos por alunas na Disciplina História da Educação no curso de Pedagogia, por inquietações hermenêuticas da História, por jeitos de significar a docência em encontros das Artes Visuais, pela redescoberta da docência que se faz de modo compartilhado no Ensino Superior, pela análise de relações existentes entre a compreensão das regras matemáticas por licenciandos e o ensino das mesmas por eles quando no exercício da docência, pela produção do ser educador a partir do desenvolvimento da a utoria e de saberes próprios à docência nas aulas de Desenho, desenvolvimento, avaliação e inovação de projetos de intervenção socioeducativa, pela valorização de uma cidadania intercultural inclusiva considerada a partir de especificidades políticas e socioeconômicas de tempos que estão a exigir um olhar mais atento para a diversidade, pela constituição de ações que dialogam com as juventudes e as realidades socioculturais diversas e múltiplas presentes nos espaços escolares e não-escolares. Neste espaço de registro de memórias, são compartilhadas com os leitores algumas experiências desenvolvidas em tempos históricos distintos e em espaços geográficos e institucionais variados, uma vez que autores vinculados a diferentes universidades passaram para o papel um pouco de suas artes de fazer currículo no Ensino Superior. Busca-se contribuir para a ampliação e problematização do debate acerca das relações que se instituem entre a formação de professores e o currículo, protagonizadas tanto por licenciandos em seu tempo de Formação Inicial, nos Cursos de Graduação, quanto por professores da Educação Básica em sua Formação Continuada, nos Cursos de Pós-Graduação Lato Sensu.

Palavras-chave: Formação docente; Licenciatura; Cultura; Educação Básica; Ensino Superior.

\section{Teachers Training and Cultural Practices: Findings, links and experimentations.}

Abstract: The dossier Formação de professores e práticas culturais (Teachers training and cultural practices) is composed by nine texts which consider the established interface between teacher training, major and courses performed by teachers that work in basic education. It is intended as a space of socialization of work proposed by professors who take different theoretical perspectives, however approaching the commitment made with the daily history of the school, of undergraduates in their concerns, of teachers as an invention that is (re) made from the rigorous exercise of research and reflection on its own practice. This dossier expresses a plurality of voices and conceptions, practices and linkages in the daily lives of Faculty formation from the perspective of the university in its dialogue with school spaces in its plural cultures, views and voices. A plurality of experimentations on which the authors tell us and that they also transit through memorials produced by students in the Discipline History of Education in the Pedagogy course, of hermeneutics concerns of history, of ways to signify the teaching encounters in Visual Arts, of the rediscovery of the faculty which is shared during the tertiary education, of the analysis of existent relationship between the undergraduates' comprehension of mathematical rules and their teaching during the teaching profession, of the educator's production from the development of their own authorship and knowledge to the faculty in design, development, evaluation and innovation of projects from socioeducative interventions, of the appreciation of intercultural inclusive citizenship considered from the specific political and socioeconomic times that are demanding a closer look for diversity, of the constitution of actions that converse with the youths and the multiple and various socio-cultural realities present in school and non-school areas. In this space of recorded memories, are shared with readers some experiences developed in distinguished historical times and assorted institutional geographical areas, since authors from different universities recorded on paper their arts of doing curriculum in the tertiary education. We seek to contribute to the expansion of the debate about the relationships instituted among training teacher and the curriculum, protagonized much for undergraduates in Initial 
Training in undergraduate courses, as per the Basic Education teachers in their Continuing Education in Postgraduate Sensu Lato.

Key words: teacher training; undergraduate; culture; basic education; itinerary education.

\section{Formación de Profesores y Prácticas Culturales: descubrimientos, enlaces, experimentaciones}

Resumen: El Dossier Formación de profesores y prácticas culturales consta de nueve textos que consideran las interfaces que se establecen entre la formación docente, las graduaciones y los cursos realizados por los docentes que trabajan en la Educación Básica. Está concebido como un espacio de socialización de trabajos propuestos por los profesores universitarios que asumen diferentes perspectivas teóricas, y que se acerca por el compromiso firmado con las historias del cotidiano de la escuela, de los profesores en sus preocupaciones y perplejidades, de la docencia como una invención que se (re) hace a partir del ejercicio riguroso de la investigación y la reflexión sobre la propia práctica. Este Dossier expresa una pluralidad de voces y concepciones, prácticas y enlaces presentes en lo cotidiano de la Formación Docente desde la perspectiva de la universidad en su diálogo con los espacios escolares plurales de sus culturas, miradas y voces. Una pluralidad de ensayos sobre los cuales nos hablan los autores y que transitan a través de memoriales producidos por las alumnas de la disciplina Historia de la Educación en el Curso de Pedagogía, por inquietudes hermenéuticas de la Historia, por modos de significar la docencia en encuentros de las Artes Visuales, por el redescubrimiento de la docencia que se hace de forma compartida en la Educación Superior, por el análisis de las relaciones existentes entre la comprensión de las reglas matemáticas por estudiantes universitarios y la enseñanza de las mismas por ellos cuando en la profesión docente, por la producción del ser educador a partir del desarrollo de la autoría y de saberes propios a la docencia en las clases de dibujo, desarrollo, evaluación e innovación de proyectos de intervención socioeducativa, por la valoración de una ciudadanía intercultural inclusiva considerada a partir de especificidades políticas y socioeconómicas de tiempos que exigen una mirada más atenta a la diversidad, por la constitución de acciones que dialogan con las juventudes y las realidades socio-culturales diversas y múltiples presentes en los espacios escolares y no escolares. En este espacio de registro de memorias, se comparten con los lectores algunas experiencias desarrolladas en tiempos históricos distintos y en espacios geográficos e institucionales, variados, una vez que los autores de diferentes universidades pusieron en el papel un poco de sus artes de hacer currículum en la Enseñanza Superior. Se trata de contribuir a la expansión y problematización del debate acerca de las relaciones que se instituyen entre la formación de profesores y el currículum, protagonizadas tanto por los estudiantes en su tiempo de Formación Inicial, en los cursos de graduación, como por los maestros de Educación Básica en su Formación Continuada, en los cursos de Postgrado Lato Sensu.

Palabras clave: Formación de Profesores; Licenciatura; Cultura; Educación Básica; Enseñanza Superior.

\section{Um pouco da história desse Dossiê}

Há pouco mais de um ano, professoras ${ }^{1}$ da Faculdade de Educação (FACED) da Universidade Federal do Rio Grande do Sul (UFRGS), Brasil, se colocaram o desafio de organizar

\footnotetext{
${ }^{1}$ Carla Beatriz Meinerz, à época do início dos trabalhos de organização deste Dossiê (primeiros meses de 2012), era Coordenadora dos Estágios na UFRGS. Hoje continua atuando nos estágios de docência em História para o Ensino Fundamental e Médio, tendo concluído seu tempo de Coordenação. Dóris Maria Luzzardi Fiss é professora responsável por uma "disciplina pedagógica" - Educaşão Contemporânea: currículo, didática, planejamento - e coordena ações de extensão diretamente vinculadas à formação de professores da
} 
um espaço de socialização de produções que consideram as interfaces estabelecidas entre a formação de professores, as licenciaturas e os cursos realizados por docentes que atuam na Educação Básica. Os professores universitários convidados a participar, embora assumam perspectivas teoricamente distintas, se aproximam pelo compromisso assumido com as histórias do cotidiano da escola, dos licenciandos em suas inquietações e estarrecimentos, da docência como invenção que se (re)faz a partir de exercício rigoroso de pesquisa e reflexão sobre a própria prática. Este Dossiê, sobre a Formação Inicial e Continuada dos Professores, se traduz como materialização de um trabalho que envolveu leitura, estudo, pesquisa, escuta de colegas e interlocução com eles sobre suas visões a respeito da ação docente e seu desejo de constituição de um espaço de registro de nossas memórias relativamente aos processos de formação nos quais estamos inscritos. Processos que envolvem o trabalho com licenciandos de diferentes áreas de conhecimento ${ }^{2}$, vinculando-se às chamadas "disciplinas pedagógicas", e com professores que atuam na Educação Básica.

O termo "disciplinas pedagógicas" é mencionado no Art. $12 \$ 3^{\circ}$ da Resolução CNE/CP N ${ }^{\circ}$ 1, de 18 de fevereiro de 2002, que institui as Diretriz̨es Curriculares Nacionais para a Formação de Professores de Educação Básica ${ }^{3}$. Depreende-se, deste documento, que tais disciplinas estão relacionadas às dimensões pedagógicas (funcionamento da escola, práticas curriculares, estágios de docência, legislação e políticas públicas, realidade da educação no país entre outros aspectos pertinentes aos espaços escolares e não-escolares) enquanto as disciplinas específicas discorrem sobre objetos de ensino ou conteúdos próprios a cada licenciatura - por exemplo, Ontologia no Curso de Filosofia, Cálculo no Curso de Matemática, Teoria Literária no Curso de Letras, História do Brasil no Curso de História, e assim por diante.

A Resolução Nº 04/2004, referente às Diretrizes para o Plano Pedagógico das Licenciaturas da UFRGS, destaca a necessidade de os cursos constituírem projeto pedagógico específico e identidade própria compreendida como: “[...] um conjunto de conhecimento e práticas envolvendo saberes e competências específicas e pedagógicas que irão constituir o perfil do futuro professor" (UFRGS, 2004). Neste documento, não são empregados os termos "disciplinas pedagógicas" ou "disciplinas específicas", mas seus significados estão subentendidos na exigência de que se estabeleça "articulação entre a teoria e a prática tanto na formação pedagógica quanto na formação específica". Ademais, garante-se que as atividades práticas de ensino e aprendizagem terão a duração de 400 horas, comprometendo-se com o desenvolvimento de trabalhos a partir dos quais os licenciandos produzam investigações e se instrumentalizem para o exercício da docência. A oferta das "disciplinas

Educação Básica. Sônia Mara Moreira Ogiba também é professora responsável por "disciplinas pedagógicas" - Educação Contemporânea: currículo, didática, planejamento e Teoria de Curriculo,- além de coordenar a Área de Didática e integrar a Chefia do Departamento de Ensino e Currículo. As três professoras coordenam pesquisas associadas à Formação de Professores.

2 Na Faculdade de Educação, em função do trabalho com as chamadas "disciplinas pedagógicas", nós estabelecemos relação com vários Cursos - Artes Visuais, Artes Dramáticas, Artes Plásticas, Ciências Biológicas, Ciências Sociais, Dança, Educação Física, Enfermagem, Filosofia, Física, Geografia, História, Letras, Matemática, Música, Pedagogia, Psicologia e Química.

${ }^{3}$ As Diretrizes Curriculares Nacionais para a Formação de Professores da Educação Básica se constituem em um “[...] conjunto de princípios, fundamentos e procedimentos a serem observados na organização institucional e curricular de cada estabelecimento de ensino" (Art. $1^{\circ}$ ), aplicando-se a todas as etapas e modalidades da Educação Básica. Elas estabelecem que a organização curricular das instituições deve considerar o preparo para "o ensino visando à aprendizagem do aluno; o acolhimento e o trato da diversidade; o exercício de atividades de enriquecimento cultural; o aprimoramento em práticas investigativas; a elaboração e a execução de projetos de desenvolvimento dos conteúdos curriculares; o uso de tecnologias da informação e da comunicação e de metodologias, estratégias e materiais de apoio inovadores; o desenvolvimento de hábitos de colaboração e de trabalho em equipe" (Art. $2^{\circ}$ ). 
pedagógicas", na FACED, está distribuída entre os três departamentos que compõem a Unidade Acadêmica: DEC (Departamento de Ensino e Currículo), DEE (Departamento de Estudos Especializados) e DEBAS (Departamento de Estudos Básicos).

Neste espaço de registro de memórias, queremos compartilhar com os leitores algumas experiências desenvolvidas em tempos históricos distintos e em espaços geográficos e institucionais variados, uma vez que autores vinculados a diferentes universidades passaram para o papel um pouco de suas artes de fazer currículo no Ensino Superior. Buscamos contribuir para a ampliação e problematização do debate acerca das relações que se instituem entre a formação de professores e o currículo, protagonizadas tanto por licenciandos em seu tempo de Formação Inicial, nos Cursos de Graduação, quanto por professores da Educação Básica em sua Formação Continuada, nos Cursos de Pós-Graduação Lato Sensu. Compreendendo que essas relações se fazem em redes tecidas entre diferentes contextos (a prática pedagógica, o trabalho coletivo na escola, a formação acadêmica, a formação continuada, a pesquisa em educação, dentre outros) e práticas culturais (a pluralidade religiosa, de gênero, de raça, de classe e assim por diante), nos preocupamos em compilar produções que deem visibilidade a essa rede e a um compromisso comum - a argumentação em favor de uma perspectiva que assume a indissociabilidade entre docência e pesquisa.

Além disso, num segundo momento, e porque todas as narrativas referem trabalhos que se articulam, direta ou indiretamente, às Licenciaturas, se fará um resgate da história mais recente da Licenciatura no Brasil, considerando, sobretudo, os movimentos protagonizados na Universidade Federal do Rio Grande do Sul, UFRGS, em diálogo com as demais instituições de ensino superior do país.

\section{Vozes e autorias: histórias contadas por professores universitários}

Doris Bittencourt Almeida, no artigo Espaço de formação docente: aulas de História da Educação, explicita seus referenciais e revisita suas práticas no Ensino Superior, especificamente na disciplina de História da Educação, dentro do processo de formação de professores no Curso de Pedagogia da Universidade Federal do Rio Grande do Sul (UFRGS). Em seu texto, encontramos uma argumentação em torno da construção da História da Educação como uma área na qual a pesquisa e a docência são temáticas e práticas indissociáveis uma da outra. Através de análise historiográfica, apresenta as perspectivas e abordagens teórico-metodológicas em composição na atualidade, representadas por objetos de estudo que incorporam os sujeitos envolvidos na educação, as discursividades e materialidades que perpassam suas vidas, seu cotidiano, enfim, suas relações com o mundo.

A História da Educação, disciplina do Curso de Pedagogia, é percebida como instituinte de processos de análise de natureza histórica em relação à educação e aos processos de escolarização, compreendendo conceitos como alteridade, tempo, espaço, relações sociais, historiografia, dentre outros. Esses processos analíticos constroem-se a partir de exercícios de estabelecimento de conexões e rememorações que incorporam as histórias de vida dos licenciandos, suas ancestralidades, suas trajetórias até então silenciadas em aspectos vinculados a questões como classe social, etnia, gênero, articulando experiências individuais e coletivas a partir das quais o sujeito é considerado na relação com seus contextos socioculturais e econômicos. Para Almeida,

[...] a disciplina História da Educação deve ir muito além da perspectiva de apenas apresentar biografias de notáveis educadores europeus, em sua grande maioria, ou constatar os fundamentos pedagógicos em uma sequência cronológica, baseada na linearidade dos fatos, apenas evidenciando a descrição dos acontecimentos havidos, apartada da realidade 
imediata. A História da Educação é parte integrante da história total, deve abandonar uma perspectiva institucional estreita de maneira a integrar o conjunto das dimensões econômica, social e política, deve refutar a narração gloriosa de um progresso continuamente assegurado pela escola. Mas, para essa disciplina conseguir acrescentar algo para os estudantes, é preciso que se distancie de um discurso dominante e procure aproximar-se dos saberes e dos anseios dos alunos. Portanto, precisa estar atrelada às vivências e realidades educacionais do país na contemporaneidade.

Em perspectiva teórica diferenciada, pensando a partir da filosofia hermenêutica e de seu cruzamento no campo do ensino de História, e da própria trajetória docente na Educação Básica e no Ensino Superior, como professora no Curso de Pedagogia na Universidade Federal de Santa Catarina (UFSC), Rosana Silva de Moura nos convida a tratar os múltiplos sentidos que uma aula de História pode ter e a importância dessa premissa na formação dos professores. No artigo $A$ Licenciatura em História: lugar hermenêutico para pensar sentidos de uma aula, a autora aponta para a formação como autoformação, afirmando que o professor deve "[...] ocupar-se em pensar o valor da aula de História desde a Educação Básica” com base no entendimento de que "[...] a vida e a história são processos densos e complexos de continuidades, rupturas, intervalos".

Luciana Gruppelli Loponte, em Arte para a docência: estética e criação na formação docente, ao revisitar trabalhos realizados nas disciplinas de Didática de Cursos de Licenciatura, da Universidade Federal do Rio Grande do Sul (UFRGS), e provocações advindas de produções artísticas diversas tais como a obra "As meninas", de Diego Velázquez, e a exposição "Cuide de você", de Sophie Calle, propõe como possível o estabelecimento de relações entre arte, estética e formação docente em qualquer área de conhecimento. A autora também se declara preocupada com o modo como “[...] a docência, ao estar imersa em um discurso pedagógico prescritivo e sensato, deixa-se impregnar pouco pelas provocações que a arte nos traz".

Em suas ações, pesquisa e prática educativa aparecem como indissociáveis, como parte de um fazer cotidiano respingado, em alguns momentos, pela vertigem e pelas piruetas da artistagem que reconhecem a docência como uma invenção social, historicamente contextualizada, a qual pode potencializar-se quando procuramos e encontramos nela espaços de criação e reinvenção. Segundo a autora:

Olhar e pensar a docência esteticamente, como uma "obra de arte", é de alguma forma assumir uma cena docente feita de dificuldades, dissonâncias, resistências, frustrações, erros, acertos, mudanças de rumo, dúvidas, incertezas, conquistas, sucessos. E aí podemos dizer que a docência pode, sim, aprender muito com os artistas, parafraseando o filósofo Nietzsche no aforismo intitulado justamente "O que devemos aprender com os artistas", se pensamos com ele que queremos ser "os poetas-autores de nossas vidas".

O professor, assim, deixa de ser compreendido como parte de uma coletividade com características homogêneas e começa a ser tratado em sua pluralidade e heterogeneidade de experiências também estéticas, portanto, em diálogo com a existência dos sujeitos, com seus modos de vida.

Sob certo aspecto, Dóris Bittencourt Almeida, Rosana Silva de Moura e Luciana Gruppelli Loponte manifestam modos singulares de negociação com as diferenças culturais presentes nos espaços de Formação Docente Inicial e Continuada. Modos que se desdobram em possibilidades outras de produção do currículo, dos saberes, das memórias e dos fazeres a partir dos enlaces que as autoras constituem com os licenciandos, com os professores da Educação Básica. Modos sobre os quais também nos falam Gilberto Ferreira da Silva e Maria Rosa Fontebasso. 
No artigo Memórias traduridas: docência compartilhada no processo de formação inicial de professores, os autores referem experiência de docência compartilhada, em Disciplinas do Curso de Pedagogia da Universidade Estadual do Rio Grande do Sul (UERGS), e suas ressonâncias sobre a produção de alternativas curriculares no Ensino Superior. Eles assim justificam a escolha pela tradução de memórias para falar sobre a Formação Docente:

Ao narrar uma experiência, criamos uma espécie de temporalidade presente, atualizando o passado e, no nosso caso, procurando retirar desse passado presentificado aprendizagens que contribuíram para a nossa ação docente, principalmente no que se refere à atuação nos processos de formação inicial de professores, e que ganham evidências também nas práticas de formação continuada.

Em sua narrativa, a "[...] vivência de docência compartilhada como fator de enriquecimento pedagógico e amplitude de abordagens, exercitando na prática a ideia do diálogo permanente entre professor-professor e professor-aluno", corresponde à vivência de protagonismo docente, na ruptura com estruturas curriculares mais tradicionais, e de mobilização da memória, no processo de retomada do acontecimento vivido, como elemento potencial "para repensar e atualizar o que se faz em educação".

A investigação, relatada no texto $A$ compreensão de regras matemáticas na formação docente: uma pesquisa sob o ponto de vista da linguagem, de Marisa Rosâni Abreu da Silveira e Paulo Vilhena da Silva, se propôs analisar os problemas percebidos na compreensão das regras matemáticas por estudantes de uma turma do Curso de Licenciatura em Matemática da Universidade Federal do Pará (UFPA) - o que se justifica se for considerado que é por meio destas interpretações que os seus futuros alunos aprenderão. Os autores mencionam alguns impasses com que os professores se deparam, advertindo que, consoante discursos produzidos a respeito da Matemática na escola, tais embaraços são de diferentes naturezas e envolvem ora o aluno sobre o qual se diz que "não aprende", ora o professor que é responsabilizado por um suposto não-ensino, ora as teorias educacionais que não garantem o sucesso supostamente prometido tanto na aprendizagem quanto no ensino.

No entanto, lançam questionamentos na direção destes discursos, argumentando que "Os professores de Matemática aderem a diferentes tendências da Educação Matemática, muitas vezes, sem conhecer seus fundamentos teóricos", e esquecem que, "ao aderir a uma teoria, é preciso conhecer as críticas feitas a ela”. Portanto, os impasses na história da Matemática na escola não podem ser reduzidos à identificação de prováveis mazelas no aluno, no professor ou nas teorias que orientam a ação deste. A docência demanda atualização constante, estudo, pesquisa, busca de alternativas e novas perspectivas que auxiliem na tarefa de ensinar Matemática. Neste sentido, a Formação Inicial dos educadores, sobre a qual eles mesmos têm responsabilidade, é de fundamental importância para o êxito de sua ação na escola, conquanto não possa garanti-lo. Dito de outra forma, a história da Matemática na escola está atravessada pelas histórias de formação dos licenciandos que serão, daqui a pouco, professores na escola.

Envolvidos em pesquisa que foca os contextos de formação dos licenciandos do Curso de Matemática, os autores confirmam sua aposta numa docência universitária comprometida com pressupostos outros que avançam em relação à compreensão da busca de conhecimentos como uma ação simples que envolveria abastecer-se de informações, pela sua acumulação, sem se sentir convocado a produzir reflexão rigorosa sobre tais conhecimentos e informações.

Nieves Blanco García e Eduardo Sierra Neto, professores da Universidade de Málaga (Espanha), que atuam na Formação Inicial de educadores sociais, no artigo La experiencia como eje de la formación: uma propuesta de formación inicial de educadoras y educadores sociales, nos convidam a pensar a respeito da formação para a docência como algo que extrapola os saberes práticos e os conhecimentos específicos do fazer educativo - sem excluí-los, construindo-se também a partir do 
desenvolvimento da autoria e dos saberes próprios do professor em formação. O texto se traduz como análise de uma experiência de docência no Ensino Superior, apresentando uma proposta de Formação Docente Inicial na Graduação em Educação Social da Universidade de Barcelona (Espanha), desenvolvida na disciplina Desenho, desenvolvimento, avaliação e inovação de projetos de intervenção socioeducativa. Para os autores,

El sentido de la formación inicial es ayudar a que las alumnas y los alumnos desarrollen sus modos propios de pensar, de actuar, explicitando y reflexionando sobre los principios que orientan sus acciones. Por tanto, consideramos que nuestro papel como enseñantes es favorecer que las y los estudiantes puedan formar-se, conocer-se, que desarrollen un saber vivo, encarnado, donde el saber, el hacer y el ser se presentan unidos.

Em seu texto, tratam dos saberes da experiência construídos no ensino universitário, na Formação Docente Inicial. Para os autores, “[...] como propuesta formativa, la exploración reflexiva de la experiencia trata de ser una mediación entre nuestras ideas, convicciones, posiciones morales y emocionales, y nuestra acciones (o propuestas de acción)". Produzem uma argumentação em torno do valor dos saberes de experiência, considerando que a Universidade deve elaborar um conhecimento pedagógico capaz de se conectar com a experiência viva dos sujeitos em Formação Inicial, educadores em potencial. A aprendizagem é compreendida desde o ponto de vista relacional, das trocas de saberes, das trocas culturais e do conhecimento socialmente construído e individualmente apropriado.

O trabalho conta do propósito de organizar a Formação Docente Inicial, buscando favorecer que os estudantes criem seus próprios saberes pelo exercício de reflexão sobre os mesmos. Portanto, em certa medida, Garcia e Nieto dialogam com Silveira e Silva na medida em que aproximam as histórias de Formação Inicial dos estudantes de outras histórias - aquelas que irão protagonizar na instituição educativa quando professores, valorizando suas experiências como mais do que vivências relacionadas apenas à dimensão da transmissão do conhecimento. Estes autores pensam tais experiências como ligadas à vida dos sujeitos, às suas escolhas, a aprendizagens transformadoras de suas vidas de professores que estão sempre a ser, também, aprendizes.

Maria Angeles Marin, ao tratar das especificidades políticas e socioeconômicas constituídas a partir da globalização, no artigo La construcción de uma ciudadanía intercultural inclusiva: istrumentos para su exploración, complementa a problematização estabelecida por Blanco e Nieto, advertindo que

El fenómeno de la pluralidady la multiculturalidad pone en cuestión el modelo homogenizador nacional de la concepción tradicional de ciudadanía. Desde el reconocimiento del valor de la diversidad (cultural, étnica, racial, de género, de preferencia sexual etc.) se hace necesario desarrollar una concepción de ciudadanía no discriminatoria que apueste por el reconocimiento de la riqueza que supone construir el espacio comunitario desde la diferencia.

A autora, ao propor o conceito de cidadania intercultural, constitui duas demandas para a Universidade: favorecer a plena integração das diferentes culturas que co-existem e produzir uma educação que valorize os ricos (porque múltiplos e variados) contextos culturais a partir dos quais os sujeitos se significam, reconhecendo o "valor de la diversidad (cultural, étnica, racial, de género, de preferencia sexual etc.)" e contribuindo, então, para uma educação identificada com uma cidadania intercultural inclusiva que "[...] puede contribuir a la transformación social, si se vive como un proceso dinámico, que desborda ampliamente los aprendizajes escolares para vincularse a la realidad social y política con una intencionalidad claramente transformadora".

Analise da Silva, professora do Curso de Pedagogia da Universidade Federal de Minas Gerais (UFMG), no artigo Educadores de jovens trabalhadores que estudam: aprendendo a ensinar, retoma 
experiência de acompanhamento e orientação de Projetos de Ação desenvolvidos por educadores de jovens e adultos que atuam em escolas municipais de Minais Gerais e realizaram Formação Continuada por meio do Curso de Pós-Graduação Especialização Lato Sensu em Docência da EJA na Educação Básica. Segundo ela,

As juventudes presentes na EJA apresentam especificidades e são caracterizadas pela diversidade. São sujeitos que compartilham ideias, anseios, angústias, planos futuros, experiências, são sujeitos que acessam bens tecnológicos e de consumo, e estão cada vez mais unidos de acordo com as identidades que trazem consigo e suas experiências de vida. É desejável que o espaço escolar e, em especial, a EJA considerem tais características, para que não se silenciem, mais uma vez, esses sujeitos de direitos. Observamos que, quando em sua prática o educador tem um olhar para a diversidade do educando, este se revela.

Em outras palavras, ao descrever os educandos que habitam as aulas dos professorescursistas, a autora destaca a necessidade de que, nos processos de Formação Docente Continuada, se constituam ações atentas à diversidade cultural presente na escola, levando em consideração as realidades socioculturais diversas e múltiplas que estão ali representadas. A instituição educativa é tomada, portanto, como um espaço sociocultural; os educandos e os educadores, como sujeitos socioculturais que exercem sua atividade e se constituem como tais em contextos sociais e históricos. Sujeitos contemporâneos que são de seu próprio tempo e, simultaneamente, carregando e carregados de memórias que trazem de outros tempos, outros grupos, outros jeitos de estabelecer e compreender as relações geracionais, étnico-raciais, religiosas, econômicas, de gênero a partir das quais se dizem e se fazem.

Além disso, fica clara, neste artigo e em outros que compõem este Dossiê, uma ideia também fundamental nos espaços de formação: a de que, para se compreender a docência, não é possível separá-la dos locais em que ela se faz - os espaços escolares e não-escolares. Portanto, compreender a docência, seja na Educação de Jovens e Adultos, seja em qualquer outra modalidade, requer um olhar atento à escola e à complexidade do trabalho educativo, considerando realidades, experiências, vozes e saberes dos protagonistas desta história que, neste caso, é escrita tanto pelos professores universitários quanto pelos licenciandos e pelos professores que já estão na escola.

\section{Narrativas de professores universitários: enlaces e contextos}

\section{O professor e suas artes de ofício: os enlaces}

Pensar a docência é tematizar efemeridades, sensibilidades, saberes e experiências singulares constituintes de trajetórias pessoais e profissionais no campo dos processos de escolarização, sejam na Educação Básica ou no Ensino Superior. O professor se depara com um paradoxo na medida em que, por vezes, ainda dissocia suas trajetórias pessoais e suas vivências anteriores de escolarização da sua formação acadêmica e das práticas culturais escolares e profissionais, inseridas em contextos de políticas econômicas nacionais e internacionais. Segundo António Nóvoa (2003; 2007; 2009), é impossível, na docência, separar as dimensões pessoais e profissionais, portanto, ensinamos aquilo que somos e, assim, assumimos uma profissão que exige um pensar a si mesmo. O educador necessita uma formação que incorpore o diálogo com diferentes profissionais de sua área e com os saberes por eles construídos na diversidade de suas experiências. Nóvoa (2003; 2007; 2009) defende a Formação de Professores construída dentro da profissão, reconhecendo que a tecnicidade e a cientificidade do trabalho docente não esgotam toda a composição do ser educador. A Universidade 
é convidada a fazer da docência e da pesquisa campos indissociáveis e a entender o licenciando como um professor em formação, num processo de constituição laboral que é constante e contínuo.

Além disso, este autor, em seu livro Professores: imagens do futuro presente (2009), chama a atenção para o lugar que o professor ocupa, hoje, no discurso sobre a educação. Nos últimos anos, se percebeu um regresso dos professores à ribalta educativa, depois de quase quarenta anos de certa invisibilidade. Como esclarece Nóvoa (2009),

A sua importância nunca esteve em causa, mas os olhares viraram-se para outros problemas: nos anos 70, foi o tempo da racionalização do ensino, da pedagogia por objectivos, do esforço para prever, planificar, controlar; depois, nos anos 80, vieram as grandes reformas educativas, centradas na estrutura dos sistemas escolares e, muito particularmente, na engenharia do currículo; nos anos 90, dedicou-se uma atenção especial às organizações escolares, ao seu funcionamento, administração e gestão. Já perto do final do século XX, importantes estudos internacionais, comparados, alertaram para o problema das aprendizagens. [..]. E quando se fala de aprendizagens, fala-se, inevitavelmente, de professores (p. 5).

Somados a estes movimentos, duas outras questões invadem os espaços de Formação de Professores: as questões da diversidade, nas suas múltiplas facetas, que abrem caminho para uma redefinição das práticas de inclusão social e de integração escolar; e os desafios colocados pelas novas tecnologias que se relacionam à aquisição de uma capacidade intelectual de aprendizagem e de desenvolvimento, o que, de novo, coloca os professores no centro da ribalta (Castells, 2001). Em razão disso, segundo Nóvoa (2009),

Os professores reaparecem, neste início do século XXI, como elementos insubstituíveis não só na promoção das aprendizagens, mas também na construção de processos de inclusão que respondam aos desafios da diversidade e no desenvolvimento de métodos apropriados de utilização das novas tecnologias (p. 5).

A experiência entendida como ação e reflexão sobre a ação conduz a uma concepção de autoria e de construção de saberes práticos fundamentada também em autores como Maurice Tardif (2002). Ao ingressar na prática profissional, o professor carrega consigo a herança das tradições, que são os caminhos dos conhecimentos e das práticas culturais trilhados tanto no campo da educação quanto na área específica em que se coloca como mestre, assim como suas vivências pessoais. Dessa maneira, o sujeito professor transforma-se no e pelo trabalho, sendo que o trabalho "modifica a identidade do trabalhador, pois trabalhar não é somente fazer alguma coisa, mas fazer alguma coisa de si mesmo, consigo mesmo" (Tardif, 2002, p. 56). Ademais, "O saber dos professores é plural e também temporal, uma vez que [...] é adquirido no contexto de uma história de vida e de uma carreira profissional" (Tardif, 2002, p. 19) - o que o próprio autor reforça quando lembra que: [...] o saber não é uma coisa que flutua no espaço: o saber dos professores é o saber deles e está relacionado com a pessoa e a identidade deles, com a sua experiência de vida e com a sua história profissional, com as suas relações com aos alunos em sala de aula e com os outros atores escolares na escola etc. Por isso é necessário estudá-lo relacionando-os com esses elementos constitutivos do trabalho docente (Tardiff, 2002, p. 11).

A escola é ainda o espaço institucional de uma tradição histórico-cultural intensa, onde insistem modelos diversos de como, para que, para quem e o que ensinar. Portanto, é um espaço de expressão de múltiplas culturas, múltiplos olhares e múltiplas vozes. Considerando os autores dos artigos apresentados aqui e suas escritas, pode-se destacar que este Dossiê expressa, também, uma pluralidade de vozes e concepções, práticas e enlaces presentes no cotidiano da Formação Docente 
desde a perspectiva da universidade no seu diálogo com esses espaços escolares plurais em suas culturas, olhares e vozes. Uma pluralidade de experimentações que transitam pelos memoriais da História da Educaşão no curso de Pedagogia, pelas inquietações hermenêuticas da História, pelos jeitos de significar a docência nos encontros das Artes Visuais, pela redescoberta da docência que se faz de modo compartilhado no Ensino Superior, pela análise de relações existentes entre a compreensão das regras matemáticas por licenciandos e o ensino das mesmas por eles quando no exercício da docência, pela produção do ser educador a partir do desenvolvimento da autoria e de saberes próprios à docência nas aulas de Desenho, desenvolvimento, avaliação e inovação de projetos de intervenção socioeducativa, pela valorização de uma cidadania intercultural inclusiva considerada a partir de especificidades políticas e socioeconômicas de tempos que estão a exigir um olhar mais atento para a diversidade, pela constituição de ações que dialogam com as juventudes e as realidades socioculturais diversas e múltiplas presentes nos espaços escolares e não-escolares.

Nessa perspectiva, assume grande importância o reconhecimento dos dispositivos pedagógicos acionados, na produção da docência, como qualquer lugar no qual a experiência de si se constitui e se transforma, no qual se aprendem e se modificam as relações que o sujeito estabelece consigo mesmo e com os pares. Esses dispositivos terminam por produzir formas de experiência de si nas quais os indivíduos se tornam sujeitos de um modo particular. Tais dispositivos, ademais, habitam as práticas curriculares, sendo importante perceber o currículo escolar como também um artefato cultural, um sistema de significação implicado na produção de identidades e subjetividades, no contexto de relações de poder que tornam mais ou menos possível a inclusão e a exclusão, seu questionamento, sua problematização.

Falar em práticas curriculares é falar em práticas culturais também como busca de compreensão do porquê de as coisas serem como são, de terem se transformado nisto que estão sendo. É necessário tornar o familiar estranho e o estranho familiar, correr riscos e assumir práticas atravessadas por concepções de cultura associadas à valorização da vida. Práticas que, enquanto mobilizadoras de processos associados à Formação Docente, se proponham como oportunidade outra de diálogo com as trajetórias de aprendizagens constituídas por professores universitários, licenciandos e professores da Educação Básica em sua história de se fazerem educadores sob as mais variadas influências e em contextos e tempos histórico-geográficos também variados.

Práticas que transformam a escola em espaço de negociações com e entre diferenças culturais, não reduzindo a educação às práticas escolares, mas nelas incluindo as diferenças vividas nos processos protagonizados em diversas instâncias sociais com suas pedagogias próprias, uma vez que há possibilidade de prática pedagógica e de relações pedagógicas em qualquer ambiente. Práticas que compreendem os lugares de formação como, também, de provocações por meio das quais os professores universitários, os licenciandos e os professores da Educação Básica são instados a assumir uma posição de autoria e de protagonismo na sua biografia de aprendizes.

A pesquisa e a prática educativa aparecem como indissociáveis nesse fazer cotidiano e são traços comuns das escritas aqui partilhadas, ainda que nem sempre os autores comunguem dos mesmos referenciais teóricos - o que não corresponde a um problema, mas à confirmação do quanto a heterogeneidade nos campos de discussão torna ricos os processos de formação de professores sem negar-lhes sua complexidade constitutiva, sem condenar-lhes a uma questionável homogeneização. Em nosso entender, não existe outra maneira possível de enfocar a complexidade da realidade educacional, no que tange aos movimentos de Formação Docente Inicial ou Continuada, se não nos dispusermos, como diz Ferraço (2005), a “[...] estabelecer relações horizontais, democráticas e de compromisso e autoria dos conhecimentos tecidos nas pesquisas" (p. 8) e nas demais intervenções produzidas pelos professores universitários desde os lugares a partir dos quais lhes é possível significar o cotidiano da escola e da universidade. 
Os educadores que se aventuram pelos caminhos da articulação entre docência e pesquisa, estejam eles atuando na Educação Básica ou no Ensino Superior, mesmo quando as filiações teóricas não são semelhantes, se aproximam em função de certa opção assumida: a teoria não é entendida como referência à qual os sujeitos pesquisados e seus fazeres-saberes necessitam ser submetidos; são os referenciais teóricos adotados que precisam aprender a dialogar com os fazeressaberes dos sujeitos pesquisados, reconhecendo-os como co-autores de toda e qualquer prática que se produza. Nesse sentido, nas experiências narradas neste Dossiê, é possível evidenciar um sentido de autoria partilhada com os licenciandos e os professores que delas fizeram parte. Nesta articulação, a partir de referenciais distintos, os professores universitários tecem uma rede comum que aposta tanto na docência atravessada pela pesquisa quanto nos licenciandos e professores como produtores de uma história outra no cotidiano da universidade ou da escola de Educação Básica.

Em todos os artigos estão presentes certas preocupações a partir da quais, como rede, um texto se ata ao outro e, com ele, faz conexão: os processos pelos quais se produz conhecimento, as experiências e processos de Formação Docente promovidos, propostos, instaurados ao longo do tempo de curso e, sobretudo, com aqueles alunos que estão sendo (ou serão) desafiados a mergulhar no(s) mundo(s) dos espaços escolares e não-escolares por força das práticas docentes, com aqueles educadores que já estão imersos neles.

De certa forma, e cada autor ao seu modo, os textos fazem lembrar algumas ideias de António Nóvoa (2009) sobre o que faz de um professor um bom professor. Ele cita cinco elementos que precisam se fazer presentes na prática docente e, portanto, devem ser objeto de atenção nos processos de Formação Inicial e Continuada. São eles: conhecimento, cultura profissional, tato pedagógico, trabalho em equipe e compromisso social (Nóvoa, 2009, p. 15-6). Soma-se a isto outro aspecto para o qual é necessário atentar: o processo de formação, ora fundamental, envolve a transformação dos professores em diálogo com os projetos das escolas em que atuam, portanto:

A formação de professores pode desempenhar um papel importante na configuração de uma 'nova' profissionalidade docente, estimulando a emergência de uma cultura profissional no seio do professorado e de uma cultura organizacional no seio das escolas (Nóvoa, 1995, p. 24).

Fica claro, em todos os artigos, que um dos desafios que se coloca para a escola, hoje, é o de se descobrir parte da vida, que deveria, por sua vez, fazer parte do conhecimento curricular, buscando nas experiências do cotidiano o que nelas têm sido negado, silenciado, e reinventando os seus sentidos Mas qual é o desafio que se coloca para a Universidade no que se refere às práticas de Formação Docente Inicial e Continuada que antecipam e acompanham o encontro com a escola? O que disso ecoa pelas falas, pelos discursos de alunos e professores universitários ou da Educação Básica? Este Dossiê compartilha algumas respostas possíveis com o leitor: apenas respostas possíveis, não únicas nem definitivas, num caminho que todos nós estamos a construir juntos.

\section{A Educação Básica no Brasil: os contextos}

No Brasil, a Educação Básica divide-se em Ensino Fundamental e Ensino Médio. A obrigatoriedade da escola está dada apenas para o Ensino Fundamental, conforme estabelece a Lei $n^{\circ}$ 9.394/96 - Lei de Diretrizes e Bases da Educação Nacional (Brasil, 1996) quando propõe, em seu Art. $5^{\circ}$ do Título II - Do direito à Educação e do dever de educar, que

O acesso ao ensino fundamental é direito público subjetivo, podendo qualquer cidadão, grupo de cidadãos, associação comunitária, organização sindical, entidade de classe ou outra legalmente constituída, e ainda, o Ministério Público, acionar o Poder Público para exigi-lo. $\int 1^{\circ}$ Compete aos Estados e aos Municípios, em regime de colaboração, e com a assistência da União: 
I - recensear a população em idade escolar para o ensino fundamental, e os jovens e adultos que a ele não tiveram acesso;

II - fazer-lhes a chamada pública;

III - zelar, junto aos pais ou responsáveis, pela frequência à escola.

O Ensino Fundamental se realiza em 9 anos desde 2001. No Brasil, se constatou um interesse constante pela ampliação do número de anos do ensino obrigatório. A Lei $N^{o} 4.024$, de 1961, estabelecia quatro anos. Pelo Acordo de Punta Del Este e Santiago, o governo brasileiro assumiu a obrigação de estabelecer a duração de seis anos de ensino primário para todos os brasileiros, prevendo cumpri-la até 1976. Em 1971, a Lei $N^{0} 5.692$ estendeu a obrigatoriedade para oito anos. Já em 1996, a LDB sinalizou para um ensino obrigatório de nove anos, a iniciar-se aos seis anos de idade. Este se tornou meta da Educação Nacional pela Lei $N^{0} 10.172$, de 9 de janeiro de 2001, que aprovou o PNE (Plano Nacional de Educação).

A determinação que consta na Lei $N^{0} 10.172 / 2001$ de implantar progressivamente o Ensino Fundamental de nove anos, pela inclusão das crianças de seis anos de idade, tem duas intenções: "[...] oferecer maiores oportunidades de aprendizagem no período da escolarização obrigatória e assegurar que, ingressando mais cedo no sistema de ensino, as crianças prossigam nos estudos, alcançando maior nível de escolaridade" (Brasil, 2001). O PNE estabelece, ainda, que a implantação progressiva do Ensino Fundamental de nove anos, com a inclusão das crianças de seis anos, deve se dar em consonância com a universalização do atendimento na faixa etária de 7 a 14 anos. Soma-se a isto a preocupação, cada vez mais acentuada, com os modelos curriculares que, na escola que temos hoje no Brasil, se organizam, basicamente, a partir de dois modos: séries ou ciclos de formação possibilidade já acenada no Art. 23, Seção I, Capítulo II da Lei No 9394/96:

A educação básica poderá organizar-se em séries anuais, períodos semestrais, ciclos, alternância regular de períodos de estudos, grupos não-seriados, com base na idade, na competência e em outros critérios, ou por forma diversa de organização, sempre que o interesse do processo de aprendizagem assim o recomendar (Brasil, 1996).

O Ensino Médio não é obrigatório e passa por reformulação e debate intensos em todo o território brasileiro, constando atualmente de três anos ${ }^{4}$. Em 1998, Acácia Kuenzer já destacava desafios colocados pelo mundo do trabalho à educação e aos processos de formação tanto inicial quanto continuada, retomando esta discussão, depois, em Ensino Médio: construindo uma proposta para os que vivem do trabalho (Kuenzer, 2000). A autora diz que:

\footnotetext{
${ }^{4}$ Segundo estabelecem as novas Diretrizes Curriculares Nacionais para o Ensino Médio, em seu Capítulo II, Art. 14, "II - no Ensino Médio regular, a duração mínima é de 3 (três) anos, com carga horária mínima total de 2.400 (duas mil e quatrocentas) horas, tendo como referência uma carga horária anual de 800 (oitocentas) horas, distribuídas em pelo menos 200 (duzentos) dias de efetivo trabalho escolar; III - o Ensino Médio regular diurno, quando adequado aos seus estudantes, pode se organizar em regime de tempo integral com, no mínimo, 7 (sete) horas diárias; IV - no Ensino Médio regular noturno, adequado às condições de trabalhadores, respeitados os mínimos de duração e de carga horária, o projeto político-pedagógico deve atender, com qualidade, a sua singularidade, especificando uma organização curricular e metodológica diferenciada, e pode, para garantir a permanência e o sucesso destes estudantes: a) ampliar a duração do curso para mais de 3 (três) anos, com menor carga horária diária e anual, garantido o mínimo total de 2.400 (duas mil e quatrocentas) horas; V - na modalidade de Educação de Jovens e Adultos, observadas suas Diretrizes específicas, com duração mínima de 1.200 (mil e duzentas) horas, deve ser especificada uma organização curricular e metodológica diferenciada para os estudantes trabalhadores, que pode: a) ampliar seus tempos de organização escolar, com menor carga horária diária e anual, garantida sua duração mínima” (Brasil, 2012).
} 
O novo princípio educativo exige que o trabalhador/cidadão de um novo tipo domine os conteúdos básicos da ciência contemporânea; que tenha novas atitudes e comportamentos; que seja mais ético, crítico e responsável, voltado para a preservação da vida, do ambiente e para a criação de uma sociedade mais humana e igualitária (Kuenzer, 1998, p. 111).

Tais desafios habitam os debates e reformulações que se constituem a partir da consideração da organização, do modelo curricular e das funções e papéis do Ensino Médio baseados em princípios que buscam maior articulação entre pesquisa e docência, currículo e trabalho. Elementos, inclusive, que foram incluídos nas novas Diretrizes Curriculares Nacionais para o Ensino Médio ${ }^{5}$ como aspectos fundamentais a serem contemplados nas práticas curriculares propostas neste nível de ensino. A este respeito, convém citar duas concepções deste conjunto - a de trabalho e a de currículo - assim como são propostas no documento, ou seja, de modo integrado:

Art. $5^{\circ} \int 1^{\circ} \mathrm{O}$ trabalho é conceituado na sua perspectiva ontológica de transformação da natureza, como realização inerente ao ser humano e como mediação no processo de produção da sua existência.

Art. $6^{\circ} \mathrm{O}$ currículo é conceituado como a proposta de ação educativa constituída pela seleção de conhecimentos construídos pela sociedade, expressando-se por práticas escolares que se desdobram em torno de conhecimentos relevantes e pertinentes, permeadas pelas relações sociais, articulando vivências e saberes dos estudantes e contribuindo para o desenvolvimento de suas identidades e condições cognitivas e sócio-afetivas (Brasil, 2012).

A elaboração de novas Diretrizes Curriculares Nacionais para o Ensino Médio se justifica pelo surgimento de demandas educacionais outras que resultam da aceleração da produção de conhecimentos, da ampliação do acesso às informações, da criação de novos meios de comunicação, das alterações do mundo do trabalho e das mudanças de interesse dos adolescentes e jovens. Segundo Moehlecke (2012),

O uso da palavra "diversidade" parece surgir no texto das novas DCNEM como uma tentativa de acomodação de duas concepções distintas de currículo e da própria identidade do Ensino Médio. No parecer das DCNEM-2011, o desafio de se encontrar uma especificidade para o Ensino Médio não está mais na superação de dicotomias - como a formação para o trabalho versus a formação para o ensino superior - por meio da construção de um currículo unificado, mas sim pela afirmação de uma multiplicidade de significados e trajetórias possíveis de serem construídas ao longo do Ensino Médio. A acomodação de tensões e divergências gerou um modelo curricular que associa uma base unitária com uma parte diversificada, em que a formação profissional é apenas mais uma entre as várias formações possíveis (p. 55).

\footnotetext{
${ }^{5}$ Em maio de 2011, foi aprovado parecer estabelecendo novas Diretrizes Curriculares especificamente para o Ensino Médio - o Parecer CNE/CEB No 5/2011 (Brasil, 2011). Em janeiro de 2012, a Resolução No 2 definiu as novas Diretrizes Curriculares Nacionais para o Ensino Médio. Conforme esclarece o Art. $2^{\circ}$ deste documento, elas se articulam "com as Diretrizes Curriculares Nacionais Gerais para a Educação Básica e reúnem princípios, fundamentos e procedimentos, definidos pelo Conselho Nacional de Educação, para orientar as políticas públicas educacionais da União, dos Estados, do Distrito Federal e dos Municípios na elaboração, planejamento, implementação e avaliação das propostas curriculares das unidades escolares públicas e particulares que oferecem o Ensino Médio" (Brasil, 2012).
} 
Nos dias atuais, a inquietação das "juventudes" que buscam a escola e o trabalho resulta mais evidente do que no passado. Ao aprendizado dos conhecimentos escolares são conferidos significados diferentes afetados pela realidade dos estudantes. Vários movimentos sinalizam no sentido de que a escola precisa ser ressignificada para responder aos desafios colocados pelos jovens (Dayrell, 2003; 2006; Dayrell e Reis, 2007; Dayrell et allii, 2009; Dayrell e Carrano, 2003; Carrano e Martins, 2011), superando a visão dualista segundo a qual o Ensino Médio se constitui em mera passagem para a Educação Superior ou para a inserção na vida econômico-produtiva.

O ingresso na universidade pública depende de concursos públicos e de exames nacionais como Exame Nacional do Ensino Médio (ENEM) cuja utilização tende a unificar os processos seletivos das universidades públicas federais. A proposta do ENEM tem como principais objetivos democratizar as oportunidades de acesso às vagas federais de Ensino Superior, possibilitar a mobilidade acadêmica e induzir a reestruturação dos currículos do Ensino Médio (Brasil, 2013).

Diferente de outros países onde a Formação Docente Inicial se faz num momento posterior à formação específica da área de conhecimento, no Brasil o estudante que deseja optar pela docência por meio de uma formação universitária deve ingressar num curso de Licenciatura que integra disciplinas de conteúdos próprios da área de formação e disciplinas de conteúdos pedagógicos.

\section{Os Cursos de Licenciatura no Brasil}

Nos anos de 1990, a grande maioria das universidades Brasileiras esteve imbuída da revitalização dos seus cursos de Licenciatura ${ }^{6}$. Podemos dizer que foi um movimento que extrapolou os muros das universidades públicas, pois dele participaram as Secretarias de Educação, Associações de Classe e Sindicatos, Associações Científicas e algumas universidades particulares e confessionais. Sobretudo, foi um movimento direcionado à consolidação de mecanismos fortalecedores da Licenciatura como lócus de uma formação docente contemporânea à responsabilidade social com a educação das múltiplas culturas que compõem a vida em sociedade.

A década de 90, para a comunidade educacional no Brasil e em outros países, foi um tempo de grande efervescência, como podemos ver pela expressão "explosão didática" ressaltada por Cornu e Vergnioux (1992) e minuciosamente analisada por Pimenta (1994; 1996a; 1996b). Abriamse, nas Universidades e na sociedade mais ampla, espaços para que ocorresse uma retomada da história da Formação Docente e da Licenciatura, entre outras razões, em virtude "do massivo investimento na qualificação dos docentes, tanto na formação inicial quanto na formação em serviço, no contexto de reformas do ensino que generalizaram a escolarização" (1996b, p. 1). Foi também um momento de profundas incertezas quanto aos rumos da profissão docente.

No Brasil, o coletivo desse movimento não deixou de situar a histórica degradação do magistério, acelerada pelo avanço de políticas sociais de cunho neoliberal que impregnam as novas políticas públicas para a educação, na virada do novo século, conforme podemos observar nas proposições constantes em Haddad et allii (1996). De imediato, percebíamos que a educação e as instituições educacionais Brasileiras, mais uma vez, estavam diante da urgência de terem que se adaptar às novas regras do capital financeiro, da economia, através da imposição de agências como Banco Mundial e Fundo Monetário Internacional (FMI) na promoção da reforma do Estado, por meio da minimização do seu papel e do favorecimento do predomínio das regras do mercado em

${ }^{6} \mathrm{O}$ curso de Licenciatura, no Brasil, é um curso de Graduação desenvolvido por Instituições de Ensino Superior (IES), públicas ou particulares, ou em Faculdades Isoladas, que habilita para o exercício da profissão docente. O licenciando, candidato à profissão, ao final do curso obtém o título de Licenciado, apto, portanto, ao exercício do magistério. 
todos os setores sociais. Fenômeno não somente observado no contexto brasileiro, como, da mesma forma, nos vários países latino-americanos ${ }^{7}$.

Todavia, se, por um lado, foram as proposições de alteração na Lei de Diretrizes e Bases da Educação Nacional, referentes à Educação Básica e à formação dos Profissionais da Educação, já indicadas no presente Dossiê, o mote principal para a instauração desse amplo movimento de revitalização da Licenciatura nos anos 90, por outro, foi nesse contexto de promulgação da nova Lei que tivemos a oportunidade de ver reaberta a antiga discussão travada pelos professores universitários que atuamos na formação de professores, e que diz respeito ao clássico modelo de Licenciatura no Brasil, o $3+1$. Embora, na década de 70, com as profundas transformações acadêmico-administrativas pelas quais passou a universidade Brasileira, esse modelo tenha sido transformado.

No bojo dessas transformações aparecem duas grandes novidades em relação a esse modelo de Formação Docente que vigorava, digamos assim, desde a década de 30 no interior das Faculdades de Filosofia. A primeira foi a extinção do seu Departamento de Ensino, o espaço no qual se desenvolvia a formação dos professores. O Departamento de Ensino tinha sob a sua responsabilidade a oferta de um curso de Didática, condição para que os bacharéis de então viessem a obter a titulação de licenciado, de professor. E a segunda novidade diz respeito ao fato de que a Reforma das universidades Brasileiras, nos anos 70, trouxe a criação das Faculdades de Educação (ou Centros de Educação) que, além do Curso de Pedagogia, passaram a ministrar a formação pedagógica dos Cursos de Licenciatura.

A partir desse período, podemos dizer que houve certa matização do modelo $3+1$. Dispersa-se o curso de Didática (equivalente a um ano) em várias disciplinas, de natureza pedagógica, disciplinas de cunho teórico-prático, tais como Didática Geral, Psicologias da Educação, Estrutura e Funcionamento da Escola de $1^{\circ}$ e $2^{\circ}$ Graus, e as Práticas de Ensino. Estas correspondem, cada uma, ao campo específico de conhecimento no qual o professor obtinha a sua titulação de professor, ou seja, obtinha o grau de Licenciado em.

Contudo, podemos observar, sem ser o caso nesse Dossiê de discorrer sobre o tratamento que a questão obteve nos anos 80 em nosso contexto brasileiro, que a Didática se mantêm como um campo, ou área, de saber no qual são produzidos conhecimentos e saberes sobre a formação do professor. Nele são investigados temas e conteúdos relativos ao ensino-aprendizagem, à prática pedagógica, seus métodos e avaliação, conteúdos curriculares, entre outros. Um campo de saber no qual o professor é concebido como agente de mudanças sociais, culturais e políticas, conforme ilustram vários estudos e pesquisas desenvolvidas nos anos $80 / 90^{8}$, e que visavam, entre outros objetivos, a ressituar o campo Didático e implicações oriundas do seu desdobrar em disciplinas pedagógicas nos Cursos de Licenciatura.

\footnotetext{
${ }^{7} \mathrm{Na}$ década de 90, as Universidades Brasileiras fizeram parte de inúmeros Encontros, Seminários e Conferências sobre as novas políticas públicas e seus efeitos nas políticas e nos currículos universitários de Formação de Professores com as Universidades Latino-Americanas, situadas nos países integrantes do MERCOSUL - Argentina, Chile, Brasil, Uruguai, Paraguai. A Universidade Federal do Rio Grande do Sul, UFRGS, através do Programa de Pós-Graduação em Educação, Linha de Pesquisa "Formação de Professores nos países do Cone-Sul", coordenada, à época, pelo Prof ${ }^{\circ}$. Dr. Augusto Nibaldo Trivinos, participou desses Encontros, realizados anualmente nos diferentes países citados, visando a uma troca de experiências sobre a Formação Docente em seus contextose ao debate a respeito dos impactos das novas políticas sociais na educação de professores, assim como das reformas educativas em curso, nos países do Cone-Sul. ${ }^{8}$ São alguns desses estudos e pesquisas: Ogiba (1990), Oliveira (1992), Libâneo (1992) e Pimenta (1994). Outros trabalhos e pesquisas desenvolvidas por diferentes autores brasileiros constam em A DIDÁTICA EM QUESTÃO, Anais do $3^{\circ}$ Seminario, 1985, USP - Universidade de São Paulo/Faculdade de Educação.
} 
Ainda que o espírito da Reforma universitária dos anos 70 visasse à inovação desse modelo de formação dos professores no Brasil, ainda assim a concepção de justaposição de conteúdos específicos relativos a um determinado campo de conhecimento a outro campo de conhecimento o campo dos conhecimentos pedagógicos - permanecerá praticamente até os dias atuais, como iremos ver nos longos debates e querelas instaladas entre os Institutos que possuem Cursos de Licenciaturas e as Faculdades de Educação, ou Centros de Educação.

Foram debates que se estenderam em diversos fóruns de discussão, como é o caso daqueles promovidos nas Associações Científicas e de Pesquisa no campo da Educação, a saber, ANPED Associação Nacional de Pesquisa e Pós-Graduação em Educação, e ANFOPE - Associação Nacional pela Formação dos Profissionais da Educação, entre outras, com especial vigor nos anos 90 e nos inícios da primeira década deste século. Ocasião em que a realidade educacional Brasileira já está sob os efeitos da nova Lei de Diretrizes - a Lei $N^{0}$ 9.394/96, assim como da proposição de Diretrizes Curriculares para os Cursos de Graduação.

Dentre os novos desafios trazidos pela Lei $N^{0} 9.394 / 96$ e pelas novas Diretrizes Curriculares para o Ensino de Graduação (Edital SESu/MEC, No 4/97) ${ }^{9}$, destaca-se a necessidade de superação, por parte da comunidade educacional, das condições de fragmentação dos currículos de formação de professores; aponta-se para a visível separação entre teoria e prática no desenvolvimento das disciplinas integrantes desses currículos, assim como para a falta de articulação entre os Cursos de Licenciatura e a Escola Básica, gerando a separação da Formação Inicial dos licenciandos dos processos de Educação Continuada da docência. Processos que são ou vivenciados no cotidiano de trabalho do professor, nos espaços escolares e não-escolares, ou no interior da própria universidade, através de diferentes modalidades, dentre as quais se incluem Cursos de Pós-Graduação Lato Sensu, Oficinas, Seminários, disciplinas frequentadas em cursos de Graduação, entre outras.

Assim, o movimento, antes mencionado, de revitalização da Licenciatura em nossa realidade Brasileira emergiu (ainda hoje se mantém vivo em diferentes contextos universitários e nas Associações Científicas no campo da Educação), visando a refletir sobre esses desafios e, quiçá, encontrar condições institucionais e teórico-práticas que possibilitassem momentos de inflexão na Licenciatura. Muitas das universidades e demais instituições de ensino superior buscavam caminhos que lhes fornecessem elementos para a constituição de uma cultura institucional outra das Licenciaturas, capaz de ensejar novas políticas de Formação Docente.

${ }^{9}$ Com a Lei $N^{\circ}$ 9.394/96 deixa de vigorar no Ensino Superior a figura do "currículo mínimo" concebido como o instrumento legal que determinava a organização dos cursos superiores no Brasil desde a Lei $N^{o}$ 5.540/71 (lei que ensejou as alterações e reformulações do Ensino de $1^{\circ}$ e $2^{\circ}$ Graus, alterando profundamente a estrutura desses graus de Ensino no Brasil). Os currículos dos Cursos de Graduação passam a serem redefinidos por meio de Diretrizes Curriculares. Em 03 de dezembro de 1997, a SESu/MEC - Secretaria de Educação Superior do Ministério da Educação, através de Edital no 4, convida a comunidade educacional (organizações, entidades e instituições) a enviar propostas para as Diretrizes Curriculares dos Cursos de Graduação. Após, compôs uma comissão de especialistas, por curso de Graduação, cujos nomes foram indicados pelas instituições. Não ficou estabelecida, no entanto, uma comissão destinada a proposição de Diretrizes Curriculares para todos os cursos de Licenciatura, ainda que tenham sido estabelecidas as Diretrizes Curriculares Nacionais para a Formação de Professores da Educação Básica (Res. CNE/CP no 1, de 18 de fevereiro de 2002). Em estágio já bem avançado das discussões no âmbito das comissões de especialistas, a SESu/MEC nomeou um "grupo-tarefa", constituído por profesores ligados à área de Educação, com o objetivo de elaborar documento norteador para as Diretrizes Curriculares das Licenciaturas. Este é um processo que ainda está em desenvolvimento no âmbito do Ministério da Educação, e que vem mobilizando os professores, nas universidades e associações científicas, por compreenderem que as transformações na formação dos profissionais da educação precisam ser profundas e contemporâneas às mudanças pelas quais a nossa realidade Brasileira vem passando. 
Foram várias as universidades Brasileiras que se dedicaram a percorrer esses caminhos... Citá-las todas, nessa apresentação do Dossiê, com as suas respectivas proposições, experiências, embates, impasses e alternativas para seus Cursos de Licenciatura, extrapolaria os objetivos que as organizadoras do mesmo se propuseram. Contudo, para finalizar esta apresentação, e no entendimento de que as experiências desenvolvidas na maioria das nossas universidades públicas convergiram em finalidades e proposições, passamos a uma descrição sucinta da experiência desenvolvida pela Universidade Federal do Rio Grande do Sul, UFRGS. A intenção é compartilhar, com os leitores do Dossiê, algumas das estratégias teórico-metodológicas, e posturas epistemológicas, que caracterizaram o modo de inserção da UFRGS naquele movimento de revitalização que desencadeou, à época, a abertura de caminhos institucionais que visaram dialogar com os desafios antes mencionados.

Perseguindo um singular diálogo, em virtude do modo como esse foi tecido nas malhas das "diferenças e das pluralizações atuantes nas licenciaturas", a comunidade das Licenciaturas da UFRGS produziu conhecimentos e saberes sobre as possibilidades de renovação das práticas curriculares da Licenciatura. Formulou, igualmente, algumas diretrizes para a transformação desses cursos, com o intuito de contribuir para a instauração das mudanças paradigmáticas e estruturais almejadas.

\section{A (re) invenção da docência pela pesquisa ${ }^{10}$}

A Universidade Federal do Rio Grande do Sul, por meio de uma ação da sua Pró-Reitoria de Graduação, institui, no ano de 1994, um amplo fórum de discussão, congregando as Unidades que possuíam cursos de Licenciatura, a Faculdade de Educação, responsável pela formação pedagógica nas Licenciaturas, licenciandos pertencentes a esses cursos e várias Escolas da rede pública do Estado do Rio Grande do Sul.

O Fórum das Licenciaturas da UFRGS esteve, nos seus primórdios, associado ao Programa de Licenciaturas - PROLICEN, promovido pela SESu (Secretaria do Ensino Superior)/MEC, que visava a apoiar projetos de melhoria nos Cursos de Licenciatura. No entanto, mais do que a reunião de intenções e ações de projetos de ensino ou de extensão, era meta do Fórum estabelecer e fortalecer, na universidade, novo paradigma de formação de professores que harmonizasse as exigências do compromisso político do educador e do desenvolvimento da crítica associada às habilidades de ensinar e de refletir sobre seu próprio trabalho.

Os participantes do Fórum encontram, em Kincheloe (1993), Nóvoa (1992) e De Certeau (1994), contribuições teórico-práticas visando a delinear o novo paradigma. Nos dois primeiros autores, encontram a perspectiva da Formação Docente orientada para a pesquisa estabelecida por

${ }^{10}$ Pesquisa desenvolvida no âmbito do Fórum das Licenciaturas da UFRGS/Pró-Reitoria de Graduação, intitulada Novas políticas e Novas Práticas Curriculares em Formação de profesores - por um duplo movimiento das licenciaturas da UFRGS, apoiada pela FINEP - Financiadora de Estudos e Projetos, no período compreendido entre setembro de 1996 a dezembro de 1997, sob a coordenação das Professoras Mérion Campos Bordas e Sônia Mara M. Ogiba. O Relatório da pesquisa está publicado em Fascículos 14 - PROGRAD - Pró-Reitoria de Graduação/Universidade Federal do Rio Grande do Sul, sob o título: A(re)invenção da Docência - Um "Relato das Diferenças e das Pluralizações" atuantes nas licenciaturas da UFRGS. Participaram da efetivação desse

Relatório/Publicação, os seguintes professores: Sônia Mara M. Ogiba, Presidente do Fórum das Licenciaturas e Co-responsável pela Pesquisa junto à Finep; Mérion C. Bordas, Faculdade de Educação e Responsável pela Pesquisa junto à Finep; Alvaro Luiz Heidrich, Departamento de Geografia/Instituto de Geociências; Renita Klusener, Professora aposentada do Departamento de Matemática Pura e Aplicada/Instituto de Matemática; Umbelina Barreto, Departamento de Artes Visuais/Instituto de Artes. Colaboração especial: Maria Suzana M. Amoretti, Assessora de Projetos Especiais e Programas de Graduação da Pró-Reitoria de Graduação/UFRGS. 
via da articulação dinâmica entre a agência formadora (no presente contexto, a Universidade) e as escolas, de modo a que pudessem criar "redes de (auto)formação participada" que envolvesssem os licenciandos e os professores em exercício. Envolvê-los na vivência interativa do cotidiano da escola e nas artes e modos de re-inventar-se como docente, como professor.

Sobre os modos e as artes de re-inventar o cotidiano escolar, a inspiração foi buscada nas pesquisas sobre o cotidiano desenvolvidas por Michel De Certeau. Esses modos e essas artes captadas nas "mil maneiras de fazer das pessoas comuns", nas quais os sujeitos se movimentam nas redes de vigilância (redes de poderes e saberes), abrindo nelas espaços e tempos ainda não capturados pelos micro-poderes que aí operam, foram vistos como operações pelas quais o docente vai se reconstruindo ao longo da vida profissional. Operações nas quais os sujeitos (os docentes) tecem memórias, trajetórias e histórias de vida profissional. Os docentes são, assim, concebidos como sujeitos portadores de memórias sociais diversificadas por se situarem no "terreno da cultura" - um terreno habitado há muito tempo.

Desde essa tomada da Pesquisa como dispositivo formativo na formação dos licenciandos, e de uma concepção acerca do conhecimento pedagógico que o compreende como podendo ser produzido em redes (semióticas), o Fórum, após três anos de discussões, durante os quais buscava a sensibilização da comunidade para os desafios emergentes, elaborava e socializava mapeamentos dos diferentes cursos de licenciatura, ao identificar as suas produções relativas a ensino, extensão e pesquisa, se propôs a ir ao alcance da meta estabelecida, acima mencionada.

Para tanto, coordenou e desenvolveu projeto de pesquisa de natureza interdisciplinar, em sintonia com as ações desenvolvidas no Fórum e ao seu modo próprio de constituição, que apostava na multi e na interdisciplinaridade como marcas constitutivas do campo da Formação de Professores. Sobretudo, pela diversidade e pelas diferenças que nesse campo se entrelaçam, fazendo com que a riqueza e a complexidade próprias da atuação dos docentes possam vir à tona, quando o que se propõe como orientação às ações seja a possibilidade do diálogo entre os múltiplos e heterogêneos saberes que estruturam diferentes disciplinas e tempos. Assim como a possibilidade da convergência e da unidade na diversidade.

A pesquisa Finep, como também era chamada no contexto do Fórum por ter obtido apoio da FINEP - Financiadora de Estudos e Projetos, na fase de sua proposição recebeu o título de Novas políticas e novas práticas curriculares em formação de professores - por um duplo movimento das licenciaturas da UFRGS. Título que faz jus a aposta da equipe de pesquisadores na hipótese que orientou a investigação - a hipótese de um duplo movimento nas licenciaturas. Movimento que possibilita estruturar a re-invenção de saberes e conhecimentos acerca da Formação Docente, produzidos, forjados, na articulação entre Formação Inicial e Educação Continuada da docência.

Nesse métier foi Garcia (1992) quem guiou a investigação. Sua noção de "desenvolvimento profissional" explicita uma concepção de Docência na qual está implicado um longo e diferenciado processo daquele que se inicia pela Formação Inicial. Portanto, uma concepção que refere a importância de se considerar vários tempos formativos e que suscita a ideia de percursos de formação. Percursos iniciados na Formação Inicial e que se desdobrarão ao longo da vida profissional do docente. Desdobram-se em processos chamados de Educação Continuada ou, em alguns contextos socioculturais, de Educação Contínua. Em suma, o autor explicita em suas pesquisas no campo da docência, com muita clareza, o quanto é importante, para a formação dos futuros profissionais da educação, uma forte articulação do Currículo (no contexto da Pesquisa "Novas políticas..." concebido também em suas finalidades de percurso, trajetória, iniciação) da sua Formação Inicial com processos de Educação Continuada desses profissionais.

No Fórum, como no desenvolvimento da pesquisa Novas políticas e novas práticas curriculares em formação de professores - por um duplo movimento das licenciaturas da UFRGS, a articulação entre Formação Inicial e Educação Continuada foi concebida como um dispositivo de formação, entre outros 
aspectos de natureza conceitual, para evitar uma justaposição dos tempos ou momentos da formação. O que os tornaria lineares e retiraria a possibilidade de que teorias e métodos, de alguma maneira, fossem problematizados ou, em outros termos, fossem re-inventados.

Dessa perspectiva, a pesquisa, em sua complexidade interdisciplinar, entre outras razões por constituir uma comunidade que totalizou 147 integrantes - professores- pesquisadores pertencentes à Universidade e às Escolas que integravam o Fórum, estudantes das licenciaturas, participantes dos subprojetos articulados à pesquisa na condição de bolsistas de Iniciação à Docência, pela iniciação à pesquisa -, buscou extrair seus dados de duas vertentes básicas de trabalho, as "vertentes produtoras de saberes e conhecimentos".

A primeira vertente agrupou diferentes subprojetos desenvolvidos pelas equipes de professores e estudantes dos Cursos de Licenciatura em Artes Visuais, Ciências Naturais e Matemática, Geografia, Letras, Matemática, Música, Química, Pedagogia e Psicologia. E um projeto proposto pelo Centro de Ecologia do Instituto de Biociências, em parceria com o Departamento de Ensino e Currículo da Faculdade de Educação.

A segunda vertente foi integrada pelo subprojeto "Formação de Professores: currículo, cotidiano escolar e políticas de identidade docente", desenvolvido por equipe de professores e estudantes da Faculdade de Educação. Este subprojeto, além de seus objetivos específicos, foi postulado pela comunidade de pesquisadores do Fórum como núcleo do projeto Novas políticas e novas práticas curriculares em formação de professores - por um duplo movimento das licenciaturas da UFRGS, no sentido de contribuir com o aprofundamento das questões básicas dos demais subprojetos. Essa postulação ocorreu em virtude da necessidade de estabelecer vinculações entre os subprojetos com vistas aos objetivos comuns do Fórum, como também da necessidade de verificação prática da viabilidade da interdisciplinaridade proposta como um dos elementos essenciais do processo de construção da Docência.

Com a contribuição de propostas de trabalho aparentemente desconectadas, como se poderá inferir das vertentes citadas acima, o desafio no terreno do método foi encontrar mecanismos e artifícios teórico-práticos capazes de produzir os conhecimentos e saberes acerca dos modos e das artes em que a docência se constrói e se re-inventa. Construção que se realiza em um processo que vai gerando uma "desconstrução", ao deslocar perspectivas e produzir descentramentos, tanto no âmbito dos conhecimentos científicos e pedagógicos quanto nas posições discursivas dos sujeitos que habitam o cotidiano e nele operam com vistas à produção de redes de pertença, redes tecidas pelo micro-poderes e pelas micro-diferenças. Isto pelo entendimento de que o cotidiano escolar é um terreno fértil, habitado por memórias e lutas com as quais os sujeitos - professores, estudantes e licenciandos -, vão se apropriando e se reapropriando de normas, regras, valores. São essas normas, regras e valores que instituem práticas e que são, ao mesmo tempo, institucionalizados por essas práticas; vão abrindo espaços e tempos nesse cotidiano, percorrendo trajetórias, às vezes, não tão lógicas assim ao primeiro olhar. Produzem estratégias, táticas e retóricas, todas as artes por meio das quais são captadas as nuances e os matizes das micro-diferenças em uma poética de vozes e autorias que inscrevem nesse cotidiano, e nos sujeitos, a "riqueza da palavra das pessoas comuns, ordinárias".

Foi precisamente com esse cuidado, ou ainda, com essa precaução de método que a equipe de pesquisadores pôde descrever e narrar - em forma de um relato das diferenças e das pluralizações atuantes nos cotidianos das Escolas que participaram da pesquisa e, no mesmo movimento de investigação, daquelas atuantes nos cursos de Licenciatura da UFRGS - os produtos ${ }^{11}$ que

\footnotetext{
${ }^{11}$ Noção tomada emprestada das pesquisas desenvolvidas por Michel De Certeau que busca expressar aquilo $e$ o que (e o como) as práticas produzem em seus inusitados movimentos produzidos pelos fluxos das forças operadas no cotidiano. No contexto das pesquisas certeauneanas sobre o cotidiano, o que essas práticas, enquanto maneiras de fazer, produzem são produtos relativos a modos de operação ou esquemas de ação; não
} 
resultaram daquela poética, daquela invenção. Esses produtos são expressão dos conhecimentos e dos saberes produzidos sob a forma de práticas que teve, ao se seguir na trilha deixada pelas pesquisas de Michel De Certeau sobre o cotidiano, a "enganadora aparência de improvisações livres". Enganadora aparência, porque docentes e licenciandos, no contexto da pesquisa e novas práticas curriculares em formação de professores - por um duplo movimento das licenciaturas da UFRGS, ambos de posse de sua "caixa de ferramentas"12, produziram saberes. Justamente aqueles que lhes cabem reinventar tendo como suposição a incompletude das teorias e do conhecimento da própria Pedagogia. O saber pedagógico produzido pelos docentes, em seu cotidiano de trabalho, não se confunde com ela (a Pedagogia): a amplia e expande.

Ademais, em seu fazer diário, os docentes lidam com contingências da cultura e não somente com conhecimentos acabados, prontos, estabelecidos. Relacionam-se com estudantes em posição de sujeitos de desejo que, pelo fato de estarem submetidos, assim como seus professores, às leis da linguagem, da cultura, a elas reagem, produzindo alteridade.

Entre os produtos que compõem aquele relato, os acima enfatizados trouxeram à luz "redes de (auto) formação participada" protagonizadas por docentes da Universidade e das Escolas públicas e por licenciandos, conforme a convocatória feita por Antonio Nóvoa.

Convocatória de que as apresentadoras deste Dossiê se apropriaram para com a mesma tecerem os enlaces entre os vários textos que o compõem.

\section{Referências}

Brasil. Ministério da Educação (2012) Resolução Nº 02/2012. Definição das Diretrizes Curriculares Nacionais para o Ensino Médio. Brasília. Disponível em: http://www.mec.gov.br

Brasil. Ministério da Educação. (1996) Lei de Diretrizese e Bases da Educação Nacional. Lei No 93.94/96. Brasilia. Disponível em: http://www.mec.gov.br

Brasil. Ministério da Educação (2013). Novo ENEM. Brasília. Disponível em http://portal.mec.gov.br

diretamente ao sujeito que é o seu autor ou seu veículo. Estas pesquisas, ao interrogarem as práticas cotidianas, o fazem detectando aquilo que o consumidor cultural "fabrica" com imagens, representações etc. Elas detectam uma produção, uma poética. O desenvolvimento maior dessa noção o leitor encontra na Apresentação e na Introdução Geral, escrita por Luce Giard, à obra A invenção do cotidiano - artes de fažer. 12 "Caixa de ferramentas" é expressão metafórica que se depreende da maneira com a qual o pensador Michel Foucault, ao longo das suas obras, pensou a sua relação com a teoria e com a prática, bem como no modo de manejar os conceitos. Vários autores, dentre eles destacamos François Ewald e Sthephen J. Ball, utilizam esta expressão também. François Ewald, em Foucault, a Norma e o Direito (1993, p. 26), diz: "Nada de imposições, uma possibilidade entre outras; certamente que não mais verdadeira que as outras, mas talvez mais pertinente, mais eficaz, mais produtiva... E é isso que importa: não produzir algo de verdadeiro, no sentido de definitivo, absoluto, peremptório, mas dar 'peças' ou 'bocados', verdades modestas, novos relances, estranhos, que não implicam em silêncio de estupefação ou um burburinho de comentários, mas que sejam utilizáveis por outros como as chaves de uma caixa de ferramentas" (grifo das autoras desta Apresentação). Sthephen J.Ball se refere a Michel Foucault como sendo um pensador que sugeriu fazermos uso de "uma caixa de ferramentas de teorias" caso se parta da ideia (e esta parece ser a posição assumida por S. Ball) de que, "se você quiser desenvolver uma análise mais coerente e articulada do mundo, precisamos, de fato, de diferentes tipos de teoria [...]” (In: Entrevista com Sthephen J.Ball: Um diálogo sobre justiça social, pesquisa e política educacional. Disponível em: http://www.cedes.unicampo.br). 
Brasil. Ministério da Educação (2011) Parecer CNE/CBE No 05/2011. Estabelecimento das Diretrizes Curriculares Nacionais para o Ensino Médio. Brasília. Disponível em: http://www.mec.gov.br

Brasil. Ministério da Educação (2001). Plano Nacional de Educação. Lei No 10.172/2001. Brasília. Disponível em: https://www.planalto.gov.br/ccivil 03/leis/leis 2001/110172.htm

Brasil. Ministério da Educação. (2002) Resolução CP/CNE01/2002. Diretrižes Curriculares Nacionais para a Formação de Professores da Educaşão Básica, em nivel superior, curso de licenciatura, de graduação plena. Brasília. Disponível em: http://www.mec.gov.br

Carrano, P.C.R. e Martins, C.H.S. (2011) A escola diante das culturas juvenis: reconhecer para dialogar. Educação, Santa Maria, v. 36, n. 1, p. 43-56, jan./abr.

Castells, M. (2001) A galáxia internet: reflexões sobre a Internet, negócios e a sociedade. Rio de Janeiro: Jorge Zahar.

Cornu, L. e Vergnioux, A. (1992). La didactique em questions. Paris: Hachette.

De Certeau, M. (1994) A invenção do cotidiano: 1. Artes de fazer. Rio de Janeiro: Vozes.

Dayrell, J.T. (2006) A escola como espaço sociocultural. In: (org.). Múltiplos olhares sobre

educaşão e cultura. Belo Horizonte: Editora UFMG. p. 136-161.

Dayrell, J.T. (2003) O jovem como sujeito social. Revista Brasileira de Educação no 24. São Paulo, set./out./nov./dez., p. 40-52.

Dayrell, J.T e Carrano, P.C.R. (2003). Jovens no Brasil: difíceis travessias de fim de século e promessas de outro mundo. Observatório Jovem. 33 p. Disponível:

http://www.emdialogo.uff.br/sites/default/files/JOVENS BRASIL MEXICO.pdf

Dayrell, J. e Reis, J. B. (2007) Juventude e Escola: Reflexões sobre o Ensino da Sociologia no Ensino Médio. Anais do XIII Congresso Brasileiro de Sociologia. Recife.

Dayrell, J. et allii. (2009) O aluno do Ensino Médio: o jovem desconhecido. Juventude e escolarização: os sentidos do Ensino Médio. TV Escola. Ano XIX. Boletim 18. Brasília: MEC. novembro.

Ewald, F. (1993). Foucault, a Norma e o Direito. Lisboa: Veja.

Fascículos 14- PROGRAD - Pró-Reitoria de Graduação /Universidade Federal do Rio Grande do

Sul. A (re)invenção da Docência - Um "Relato das Diferenças e das Pluralizações" atuantes nas licenciaturas da

UFRGS. Porto Alegre: Gráfica UFRGS, s.d.

Ferraço, C.E. (org.). (2005) Cotidiano escolar, formação de professores(as) e currículo. São Paulo: Cortez.

Garcia, C.M. (1992). Formación del profesorado para el cambio educativo. Barcelona, P.P.U.

Haddad et alii. (1996). O Banco Mundial e as políticas educacionais. São Paulo: Cortez.

Kincheloe, J.L. (1993). A formação do professor como compromisso politico. Porto Alegre: Artes Médicas.

Kuenzer, A. (1998) A formação de educadores no contexto das mudanças do mundo do trabalho: novos desafios para as Faculdades de Educação. Educação e Sociedade, Campinas, ano XIX, n. 63, agosto.

Kuenzer, A. (2000) Ensino Médio: construindo uma proposta para os que vivem do trabalho. São Paulo: Cortez.

Libâneo, J.C. (1992). Contribuição das ciências da educação na constituição do objeto de estudo da Didática. VII Encontro Nacional de Didática e Prática de Ensino. Goiânia.

Moehlecke, S. (2012) O Ensino Médio e as Novas Diretrizes Curriculares Nacionais: entre recorrências e novas inquietações. Revista Brasileira de Educação, v. 17, n. 49, jan./abr. 2012, p. 39-58.

Nóvoa, A. (org.). (1992). Os professores e a sua formação. Porto: Porto Editora. (Temas da Educação 1)

Nóvoa, A. (org.) (1995) Os professores e a sua formação. Lisboa: Dom Quixote.

Nóvoa, A. (2009) Professores: imagens do futuro presente. Lisboa: EDUCA.

Nóvoa, A. (org.) (2003) Profissão Professor. 2. ed. Porto: Porto Editora. 
Nóvoa, A. (org.). (2007) Vidas de professores. Porto: Porto Editora.

Ogiba, S.M.M. (1990). Da "Didática em Questão" nos anos 80 à questão da Didática: seu compromisso com a formação de professores. Dissertação de Mestrado, Programa de Pós-Graduação em Educação, UFRGS.

Oliveira, M.R.N.S. (1992) A reconstrução da Didática - elementos teórico-metodológicos. Campinas: Papirus.

Pimenta, S. (1994). Educação. Pedagogia e Didática. VII Encontro Nacional de Didática e Prática de Ensino. Goiânia.

Pimenta, S. (1996a). Pedagogia, ciência da educação? São Paulo: Cortez.

Pimenta, S. (1996b). Para uma re-significação da Didática - Ciências da Educação, Pedagogia e Didática - (uma revisão conceitual e uma síntese provisória). Disponível em: WWW.educacaoonline.pro.br

Tardif, M. (2002) Saberes docentes e formação profissional. Petrópolis, RJ: Vozes.

Universidade Federal do Rio Grande do Sul. (2004) Conselho de Ensino, Pesquisa e Extensão. Resolução No 04/2004. Diretrizes para o Plano Pedagógico das Licenciaturas da UFRGS. Disponível em: http://www.ufrgs.br/cepe/legislacao/Res04-04.htm

Entrevista com Sthepen J. Ball: Um diálogo sobre justiça social, pesquisa e política educacional. Disponível em: http://www.cedes.unicampo.br 


\section{Carla Beatriz Meinerz}

\section{Sobre as Autoras}

Universidade Federal do Rio Grande do Sul

Doutora em Educação pela Universidade Federal do Rio Grande do Sul. Professora Adjunta no Departamento de Ensino e Currículo da Faculdade de Educação.

carlameinerz@gmail.com

\section{Dóris Maria Luzzardi Fiss}

Universidade Federal do Rio Grande do Sul

Doutora em Educação pela Universidade Federal do Rio Grande do Sul. Professora Adjunta no Departamento de Ensino e Currículo da Faculdade de Educação.

fiss.doris@gmail.com

\section{Sônia Mara Moreira Ogiba}

Universidade Federal do Rio Grande do Sul

Mestre em Educação pela Universidade Federal do Rio Grande do Sul. Professora do

Departamento de Ensino e Currículo da Faculdade de Educação. Membro da Associação

Psicanalítica de Porto Alegre (APPOA) e Instituto APPOA - Clínica, Pesquisa e Intervenção

Social.

ogb@cpovo.net

\section{Sobre as Editoras Convidadas}

\section{Carla Beatriz Meinerz}

Universidade Federal do Rio Grande do Sul

Doutora em Educação pela Universidade Federal do Rio Grande do Sul. Professora Adjunta no Departamento de Ensino e Currículo da Faculdade de Educação.

carlameinerz@gmail.com

\section{Dóris Maria Luzzardi Fiss}

Universidade Federal do Rio Grande do Sul

Doutora em Educação pela Universidade Federal do Rio Grande do Sul. Professora Adjunta no Departamento de Ensino e Currículo da Faculdade de Educação.

fiss.doris@gmail.com

\section{Sônia Mara Moreira Ogiba}

Universidade Federal do Rio Grande do Sul

Mestre em Educação pela Universidade Federal do Rio Grande do Sul. Professora do

Departamento de Ensino e Currículo da Faculdade de Educação. Membro da Associação

Psicanalítica de Porto Alegre (APPOA) e Instituto APPOA - Clínica, Pesquisa e Intervenção

Social.

ogb@cpovo.net 


\section{DOSSIÊ}

FORMAÇÃO DE PROFESSORES E PRÁTICAS CULTURAIS

\section{arquivos analíticos de políticas educativas}

Volume 21 Número 22 de março, 2013

ISSN 1068-2341

SOC.RE

O Copyright e retido pelo/a o autor/a (ou primeiro co-autor) que out direito da primeira publicação à revista Arquivos Analíticos de Políticas Educativas. Más informação da licença de Creative Commons encontram-se em http://creativecommons.org/licenses/by-nc-nd/2.5. Qualquer outro uso deve ser aprovado em conjunto pelo/s autor/es e por AAPE/EPAA. AAPE/EPAA é publicada por Mary Lou Fulton Institute Teachers College da Arizona State University. Os textos publicados em AAPE são indexados por CIRC (Clasificación Integrada de Revistas Científicas, Espanha) DIALNET (Espanha), Directory of Open Access Journals, Education Full Text (H.W. Wilson), EBSCO Education Research Complete, , ERIC, , QUALIS A2 (Brasil), SCImago Journal Rank; SCOPUS, SOCOLAR (China). Contribua com comentários e sugestões a http://epaa.info/wordpress/ ou para Gustavo E. Fischman fischman@asu.edu.

Curta a nossa comunidade EPAA's Facebook https://www.facebook.com/EPAAAAPE e Twitter feed@epaa_aape. 


\section{arquivos analíticos de políticas educativas conselho editorial}

Editor: Gustavo E. Fischman (Arizona State University) Editores Associados: Rosa Maria Bueno Fisher e Luis A. Gandin

(Universidade Federal do Rio Grande do Sul)

Dalila Andrade de Oliveira Universidade Federal de Minas Gerais, Brasil

Paulo Carrano Universidade Federal Fluminense, Brasil

Alicia Maria Catalano de Bonamino Pontificia Universidade Católica-Rio, Brasil

Fabiana de Amorim Marcello Universidade Luterana do Brasil, Canoas, Brasil

Alexandre Fernandez Vaz Universidade Federal de Santa Catarina, Brasil

Gaudêncio Frigotto Universidade do Estado do Rio de Janeiro, Brasil

Alfredo M Gomes Universidade Federal de Pernambuco, Brasil

Petronilha Beatriz Gonçalves e Silva Universidade Federal de São Carlos, Brasil

Nadja Herman Pontificia Universidade Católica -Rio Grande do Sul, Brasil

José Machado Pais Instituto de Ciências Sociais da Universidade de Lisboa, Portugal

Wenceslao Machado de Oliveira Jr. Universidade Estadual de Campinas, Brasil
Jefferson Mainardes Universidade Estadual de Ponta Grossa, Brasil

Luciano Mendes de Faria Filho Universidade Federal de Minas Gerais, Brasil

Lia Raquel Moreira Oliveira Universidade do Minho, Portugal

Belmira Oliveira Bueno Universidade de São Paulo, Brasil

António Teodoro Universidade Lusófona, Portugal

Pia L. Wong California State University Sacramento, U.S.A

Sandra Regina Sales Universidade Federal Rural do Rio de Janeiro, Brasil

Elba Siqueira Sá Barreto Fundação Carlos Chagas, Brasil

Manuela Terrasêca Universidade do Porto, Portugal

Robert Verhine Universidade Federal da Bahia, Brasil

Antônio A. S. Zuin Universidade Federal de São Carlos, Brasil 


\section{education policy analysis archives editorial board}

Editor Gustavo E. Fischman (Arizona State University)

Associate Editors: David R. Garcia (Arizona State University), Stephen Lawton (Arizona State University)

Rick Mintrop, (University of California, Berkeley) Jeanne M. Powers (Arizona State University)

Jessica Allen University of Colorado, Boulder

Gary Anderson New York University

Michael W. Apple University of Wisconsin, Madison

Angela Arzubiaga Arizona State University

David C. Berliner Arizona State University

Robert Bickel Marshall University

Henry Braun Boston College

Eric Camburn University of Wisconsin, Madison

Wendy C. Chi* University of Colorado, Boulder

Casey Cobb University of Connecticut

Arnold Danzig Arizona State University

Antonia Darder University of Illinois, UrbanaChampaign

Linda Darling-Hammond Stanford University

Chad d'Entremont Strategies for Children

John Diamond Harvard University

Tara Donahue Learning Point Associates

Sherman Dorn University of South Florida

Christopher Joseph Frey Bowling Green State University

Melissa Lynn Freeman* Adams State College

Amy Garrett Dikkers University of Minnesota

Gene V Glass Arizona State University

Ronald Glass University of California, Santa Cruz

Harvey Goldstein Bristol University

Jacob P. K. Gross Indiana University

Eric M. Haas WestEd

Kimberly Joy Howard* University of Southern California

Aimee Howley Ohio University

Craig Howley Ohio University

Steve Klees University of Maryland

Jaekyung Lee SUNY Buffalo
Christopher Lubienski University of Illinois, UrbanaChampaign

Sarah Lubienski University of Illinois, UrbanaChampaign

Samuel R. Lucas University of California, Berkeley

Maria Martinez-Coslo University of Texas, Arlington

William Mathis University of Colorado, Boulder

Tristan McCowan Institute of Education, London

Heinrich Mintrop University of California, Berkeley

Michele S. Moses University of Colorado, Boulder

Julianne Moss University of Melbourne

Sharon Nichols University of Texas, San Antonio

Noga O'Connor University of Iowa

João Paraskveva University of Massachusetts, Dartmouth

Laurence Parker University of Illinois, UrbanaChampaign

Susan L. Robertson Bristol University

John Rogers University of California, Los Angeles

A. G. Rud Purdue University

Felicia C. Sanders The Pennsylvania State University Janelle Scott University of California, Berkeley

Kimberly Scott Arizona State University

Dorothy Shipps Baruch College/CUNY

Maria Teresa Tatto Michigan State University

Larisa Warhol University of Connecticut

Cally Waite Social Science Research Council

John Weathers University of Colorado, Colorado Springs

Kevin Welner University of Colorado, Boulder

Ed Wiley University of Colorado, Boulder

Terrence G. Wiley Arizona State University

John Willinsky Stanford University

Kyo Yamashiro University of California, Los Angeles

* Members of the New Scholars Board 


\section{archivos analíticos de políticas educativas consejo editorial}

Editor: Gustavo E. Fischman (Arizona State University)

Editores. Asociados Alejandro Canales (UNAM) y Jesús Romero Morante (Universidad de Cantabria)

Armando Alcántara Santuario Instituto de Investigaciones sobre la Universidad y la Educación, UNAM México

Claudio Almonacid Universidad Metropolitana de Ciencias de la Educación, Chile

Pilar Arnaiz Sánchez Universidad de Murcia, España

Xavier Besalú Costa Universitat de Girona, España Jose Joaquin Brunner Universidad Diego Portales, Chile

Damián Canales Sánchez Instituto Nacional para la Evaluación de la Educación, México

María Caridad García Universidad Católica del Norte, Chile

Raimundo Cuesta Fernández IES Fray Luis de León, España

Marco Antonio Delgado Fuentes Universidad Iberoamericana, México

Inés Dussel FLACSO, Argentina

Rafael Feito Alonso Universidad Complutense de Madrid, España

Pedro Flores Crespo Universidad Iberoamericana, México

Verónica García Martínez Universidad Juárez Autónoma de Tabasco, México

Francisco F. García Pérez Universidad de Sevilla, España

Edna Luna Serrano Universidad Autónoma de Baja California, México

Alma Maldonado Departamento de Investigaciones Educativas, Centro de Investigación y de Estudios Avanzados, México

Alejandro Márquez Jiménez Instituto de Investigaciones sobre la Universidad y la Educación, UNAM México

José Felipe Martínez Fernández University of California Los Angeles, USA
Fanni Muñoz Pontificia Universidad Católica de Perú

Imanol Ordorika Instituto de Investigaciones Economicas - UNAM, México

Maria Cristina Parra Sandoval Universidad de Zulia, Venezuela

Miguel A. Pereyra Universidad de Granada, España

Monica Pini Universidad Nacional de San Martín, Argentina

Paula Razquin UNESCO, Francia

Ignacio Rivas Flores Universidad de Málaga, España

Daniel Schugurensky Universidad de Toronto-Ontario Institute of Studies in Education, Canadá

Orlando Pulido Chaves Universidad Pedagógica Nacional, Colombia

José Gregorio Rodríguez Universidad Nacional de Colombia

Miriam Rodríguez Vargas Universidad Autónoma de Tamaulipas, México

Mario Rueda Beltrán Instituto de Investigaciones sobre la Universidad y la Educación, UNAM México

José Luis San Fabián Maroto Universidad de Oviedo, España

Yengny Marisol Silva Laya Universidad Iberoamericana, México

Aida Terrón Bañuelos Universidad de Oviedo, España

Jurjo Torres Santomé Universidad de la Coruña, España

Antoni Verger Planells University of Amsterdam, Holanda

Mario Yapu Universidad Para la Investigación Estratégica, Bolivia 